\title{
Assessment on the measurement properties of the Brazilian Portuguese language version of the International Consultation on Incontinence Questionnaire Female Sexual Matters Associated with Lower Urinary Tract Symptoms Module (ICIQ-FLUTSsex)
}

Bruna Fonseca de Andrade 1

iD https://orcid.org/0000-0002-7899-0644

Leila Katz 2

https://orcid.org/0000-0001-9854-7917

Artur Eduardo de Oliveira Rangel 3

https://orcid.org/0000-0002-3623-2722

Julianna de Azevedo Guendler 4

https://orcid.org/0000-0002-2712-2599

\footnotetext{
1,3,4 Faculdade Pernambucana de Saúde. Av. Mascarenhas de Morais, 4861. Imbiribeira. Recife, PE, Brasil. CEP: 51.150-000. E-mail: jujuguendler@gmail.com 2 Instituto de Medicina Integral Prof. Fernando Figueira. Recife, PE, Brasil.
}

\begin{abstract}
Objectives: to assess internal consistency and reliability in providing a Portuguese version of the International Consultation on Incontinence Questionnaire Female Sexual Matters Associated with Lower Urinary Tract Symptoms Module (ICIQ-FLUTSsex).

Methods: a validation study was conducted by applying questionnaires for 56 women over 18 years old with active sexual life and presenting urinary incontinence, excluding those who had urinary infection in the past 6 months. Three questionnaires were used, one for personal identification; the International Consultation on Incontinence Questionnaire - Short Form (ICIQ-SF) and the ICIQ-FLUTSsex. SPSS software was used for data analysis. Cronbach's alpha was used to verify reliability of the items on the questionnaires and Kappa coefficient was used to assess the agreement between the questionnaires applied in the testretest.

Results: the median age was 49.1 years old, mostly were mixed colored skin and married, with a high prevalence of mixed urinary incontinence. Cronbach's alpha score was 0.80 , which was considered good. Kappa value was moderate, ranging from 0.36 to 0.76 .

Conclusion: internal consistency was considered good and reliability moderate. The Portuguese version of ICIQ-FLUTSsex was proven to be valid to use on women with urinary incontinence, contributing for clinical practice, as it provides as a quick tool for research on sexual dysfunction.
\end{abstract}

Key words Validation, Urinary incontinence, Questionnaire

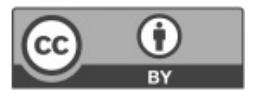




\section{Introduction}

According to the International Continence Society (ICS), Urinary Incontinence (UI) is defined as any involuntary urine loss. ${ }^{1}$ It has a multifactorial etiology and is more frequent in women. Among the main predisposing factors, there are: number of pregnancies, vaginal childbirth, climacteric, hypoestrogenism, diabetes, obesity and trauma on the pelvic floor muscles. ${ }^{2,3}$

UI is classified in three main types: (1) Stress Urinary Incontinence (SUI), when there is urine loss during some effort that increases intra-abdominal pressure, such as coughing, sneezing or physical exercise; (2) Urge Incontinence or Urgency Urinary Incontinence (UUI), is characterized by urine loss accompanied by a strong sensation of urgency to urinate; (3) Mixed Urinary Incontinence (MUI), is when there is a complaint of loss associated with urgency and also physical efforts. ${ }^{4}$

One of the hardest concerns of women with UI is their sexuality, affecting more specifically their sexual satisfaction, in which this can reduce their quality of life (QOL). Shame and acceptance are the main emotional problems faced by women with urinary incontinence, directly interfering in the couple's sexual activity. 5

Female sexual dysfunction (FSD) is characterized by a significant clinical disturbance in a person's ability to respond sexually or to experience sexual pleasure. 6 It is considered as a frequent health problem, that includes: dysfunction in sexual desire/arousal, orgasm dysfunction and genito/pelvic pain. 7

Women with incontinence have reported complaints of urinary loss during sexual intercourse, during penetration and orgasm, in addition to having difficulties in reaching orgasm, decreased desire, lubrication and satisfaction. ${ }^{8}$ Findings from a crosssectional study was carried out with 356 women on the impact of UI on female sexual dysfunction, concluded that women with UI were more likely to be sexually abstinent than continent women. In addition, these women with UI showed less desire, comfort and sexual satisfaction. ${ }^{9}$

A Brazilian study showed that $58 \%$ of women had sexual complaints, the most frequent were: lack of sexual desire (34.6\%), orgastic dysfunction $(29.3 \%)$ and pain during intercourse $(21 \%){ }^{6}$ Despite being considered as a major health problem, FSD continues to be underdiagnosed and undertreated, because as it is a disease that depends of self-reporting, either for diagnosis and treatment, valid and reliable measures by identifying it can help treat this issue, such as, the use of validated questionnaires. 7

The International Consultation on Incontinence Questionnaire Female Sexual Matters Associated with Lower Urinary Tract Symptoms Module (ICIQFLUTSsex) is a brief questionnaire that performs a detailed assessment on female sexual behavior associated with lower urinary tract symptoms and their impact on QOL. Composed of eight questions, it has the advantage of its easy and quick application contributing to its use in clinical practice worldwide. ${ }^{8}$

Other questionnaires addressing urinary incontinence and sexual dysfunction have previously been validated for the Brazilian Portuguese language version, such as the Female Sexual Function Index (FSFI) and the International Consultation on Incontinence Questionnaire- Short Form (ICIQ-SF).

The FSFI assesses the female sexual response from six domains: sexual desire, sexual arousal, vaginal lubrication, orgasm, sexual satisfaction and pain. The ICIQ-SF is used to assess the impact of UI on QOL and to qualify urinary loss in patients of both sexes. However, there is no questionnaire validated in Brazil to assess sexual complaints related to the lower urinary tract. 9,10

Although the cross-cultural adaptation of ICIQFLUTSsex in Brazil has already been published, by the authors themselves, and Congress proceedings, but the publication of the Portuguese version was not available to the public.11 Furthermore, the analysis of measurement properties (Cronbach 's alpha and Kappa) had not been performed yet. Thus, this could not be used to support the assessment on sexual dysfunction associated with lower urinary tract in Brazil or in any other Portuguese speaking countries (Figure 1).

The objective of this study was to evaluate the following measurement properties: internal consistency and reliability and to provide a Brazilian Portuguese language version of the ICIQFLUTSsex questionnaire.

\section{Methods}

The present study is part of a validation study, carried out at the Women's Physiotherapy Outpatient Clinic of the Instituto de Medicina Integral Prof. Fernando Figueira (IMIP) in Recife, Pernambuco, from April 2017 to June 2018. This study was approved by the Ethics Committee at the Faculdade Pernambuca de Saúde (CAAE: 49429915.4. 0000.5569).

The population was composed of women 
ICIQ-FLUTSsex questionnaire used to assess sexual dysfunction.

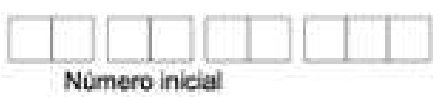

\section{ICIO-FUTSSex 0905 \\ CONFIDENCLAL}

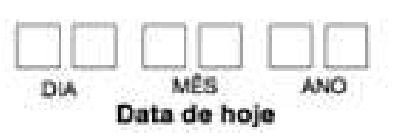

\section{Assuntos sexuais}

Nós ficarlamos agradecidos se voct pudesse responder às seguintes questoes em relaçâo a como voce tom se sentido, em modia, nas ULLTMAS QUATRO SEMANAS.

1. Por favor escreva sua data de nascimento:

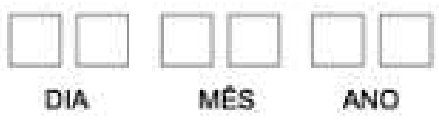

2a. Vocé sente dor ou desconforto por causa de secura vaginal?

2b. O quanto isso the incomoda?

Por favor croule um numero de 0 (nem um pouco) a 10 (demais)

$$
\begin{array}{ccccccccccc}
0 & 1 & 2 & 3 & 4 & 5 & 6 & 7 & 8 & 9 & 10 \\
\text { nam um pouco } & & & & & & & & & & \text { demais }
\end{array}
$$

3a. O quanto vocé acha que os sintomas urindrios prejudicam sua vida sexual?

nato $\square$ o

um pouco $\square$,

mais ou menos $\square=$

muito $\square$,

3b. O quanto isso the incomoda?

Por tavor circule um número de 0 (nem um pouco) a 10 (demals)

$$
\begin{array}{lllllllllll}
0 & 1 & 2 & 3 & 4 & 5 & 6 & 7 & 8 & 9 & 10
\end{array}
$$

$$
\text { nem um pouco demais }
$$

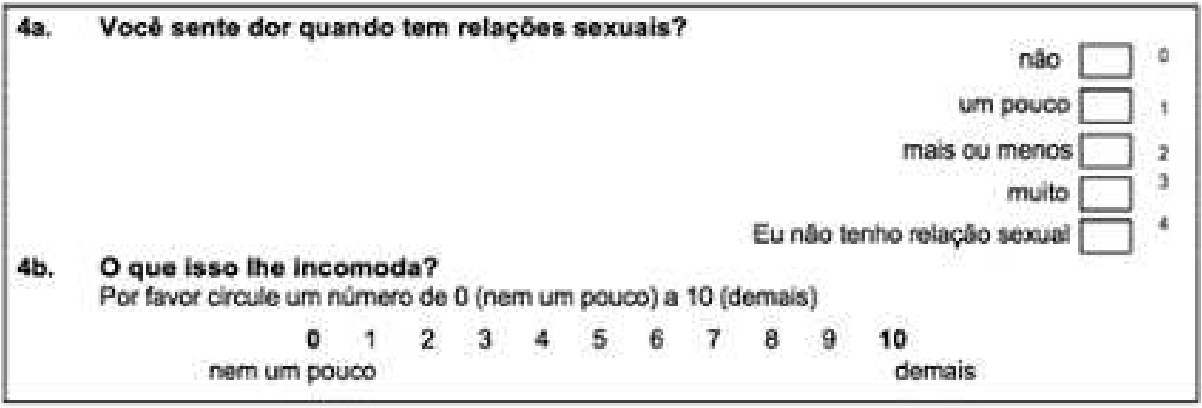

Copycont O "ICIQ Groud" : the ICQ-FLUTSsex is based on she BRUTS 


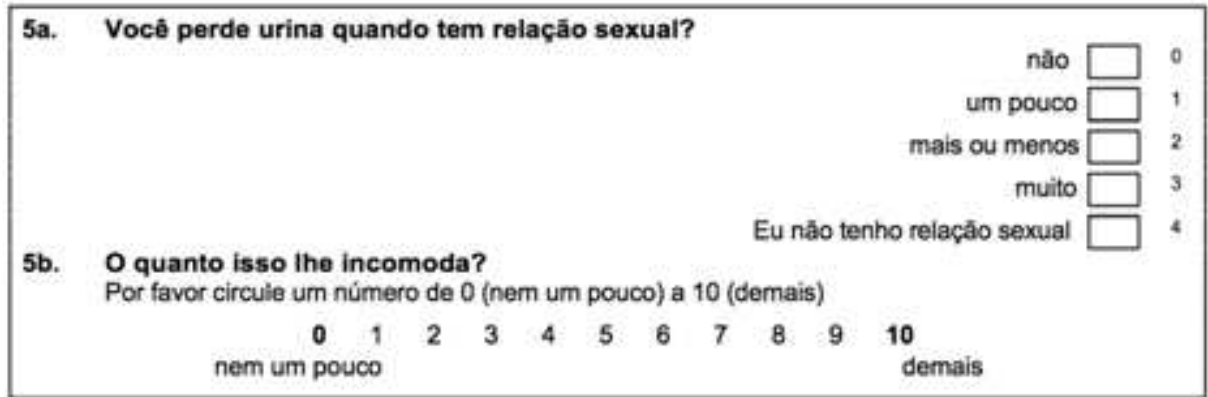

ogfuTs:

Muito obrigado por responder essas perguntas.

Copynght $O$ "CIQ Group" : the ICIQ-FLUTSsex is based on the BFLUTS

followed up from the Women's Physiotherapy Outpatient Clinic at IMIP and the inclusion criteria were: women equal or older than 18 years old, sexually active, had at least one sexual intercourse in the last four weeks and presented urinary incontinence. The only exclusion criterion was those with the presence of urinary tract infection in the past six months. The calculated sample was considered from the seven subject items on the questionnaire. 12 As the ICIQ-FLUTSsex has eight items, the final sample was composed of 56 women. In addition, according to Sapnas and Zeller, 13 a minimum of 50 subjects and a maximum of 100 are sufficient when the intention is to assess the properties of the health measurement instruments. The sampling was consecutively based on the spontaneous demand of the outpatient clinic. 13

The inclusion and validity of the information obtained by the volunteers were only included in the study after the validation of the eligibility criteria and the women's consent to participate in the research by signing of the Consent Forms.

Three instruments were used for data collection: the first was a personal identification questionnaire for sociodemographic data (age, ethnicity, marital status, education, occupation and family income), clinical (hypertension, asthma, diabetes, heart disease, primary dysmenorrhea, traumato-orthopedic pain and surgery, physical activity), obstetric (number of pregnancies, number of childbirths, types of delivery, number of abortions, children and complications during pregnancy) and gynecological (age of menarche, age of the last menstruation, previous surgeries such as tubal ligation or hysterectomy and type of incontinence).

The second was the ICIQ-SF questionnaire, used to rectify the volunteers' UI complaint, assess the impact of UI on QOF and to qualify urinary loss of the analyzed patients. The ICIQ-SF consists of four questions that assess the frequency, severity and impact of urinary incontinence, in addition to a set of eight self-diagnosis items, related to the causes or situations of UI experienced by the patients. ${ }^{10}$ For the analysis on their answers, numerical values were assigned, in which the total score varied from 0 to 21 points, and the greater the sum of points, the greater the severity and impact of UI on QOL. The impact on QOL is classified as follows: zero (0), no impact; from 1 to 3 points, mild impact; 4 to 6 points, moderate; 7 to 9 points, severe; and 10 or more points, very severe. 14

The third instrument was the ICIQ-FLUTSsex in the Brazilian Portuguese language version, a questionnaire that evaluates the sexual issues associated with lower urinary tract, composed of eight questions, of which four assess the presence of pain or discomfort due to vaginal dryness, impact of urinary incontinence in their sexual life, presence of pain 
and urine loss during sexual intercourse. The remaining questions assess how much each question disturbs them, with numerical answers ranging from 0 (not at all) to 10 (too much). The final score of the questionnaire can vary between 0 and 16 . Higher values indicate greater severity of symptoms. ${ }^{11}$

The process of cross-cultural adaptation of the instrument took place in five stages (translation, synthesis of translations, back-translation, reviewed by a committee of experts and pre-test). The results were carried out before this study and was published. ${ }^{11}$ After these stages, the questionnaire was available to be applied in order to verify its measurement properties.

The data were typed, tabulated, and analyzed by using the Statistical Package for Social Sciences (SPSS) software, version 21. To assess the internal consistency, Cronbach's alpha coefficient was calculated in order to verify the homogeneity of the items, that is, its accuracy. As a general rule, the accuracy should not be less than 0.80 if the scale is widely used, but values above 0.60 already indicate consistency between the items. 15

The reliability of applying the questionnaire was performed using test-retest, performed by the same examiner with an interval of 8 to 15 days to be repeated, starting from the first application of the qustionaire in the attempt to verify the precision of the responses. The reliability was assessed for each item separately. During the study period, the participants were undergoing physiotherapy with a weekly frequency, which facilitated the performance to do the retest

The Kappa coefficient was used to distinguish the disagreement or agreement between the assessments performed. 16 Values can be interpreted as: small ( 0.00 to 0.20$)$; regular (021 to 0.40$)$; moderate (0.41 to 0.60$)$; substantial ( 0.61 to 0.80$)$ and almost perfect (0.81 to 1.00$) .17$

\section{Results}

For this study, 80 women were evaluated for elegibility, of which two did not accept to participate because of issues that involved sexuality and 22 were excluded because they did not have an active sexual life, totaling the final sample of 56 women. The average age of the participants was 49.1 years old $(\mathrm{SD}=11.6)$. Sociodemographic characteristics showed that $40(71.4 \%)$ were married, $26(46.4 \%)$ were mixed color skin; 19 (33.9\%) graduated from high school; $31(55.4 \%)$ had an income up to a minimum wage and $32(57.1 \%)$ were employed (Table 1).

Regarding the obstetric history, 52 (92.9\%) said that they had already been pregnant, with a median of $2.71(\mathrm{SD}=1.8)$ childbirths, per participant, either vaginal or cesarean section, with means of 2.13 $(\mathrm{SD}=1.9)$ and $0.67(\mathrm{SD}=0.7)$, respectively.

Regarding to the type of incontinence, most women, $34(60.7 \%)$ had MUI, while $13(23.2 \%)$ had USI and nine (16.1\%) had UUI (Table 2). Furthermore, 39 (69.6\%) women had undergone hysterectomy.

The analysis on the UI impact on QOF, using the ICIQ-SF questionnaire, showed that 46 (82.1\%) participants had a very serious impact; seven $(12.5 \%)$ were severe; one $(1.8 \%)$ was moderate and two $(3.6 \%)$ had no impact. Investigating the frequency of urine loss, $33(58.9 \%)$ reported urine loss several times a day, $25(44.6 \%)$ responded that the amount of loss was low and the interference in their daily life, on a scale of 0 to $10,22(39.3 \%)$ scored 10 (Table 3 ).

The result of the internal consistency analysis on the ICIQ-FLUTSsex questionnaire measured by Cronbach's Alpha was 0.80 . Concerning the agreement between the answers given in the first and second ICIQ-FLUTSsex assessments (test-retest), were performed with $41(73.2 \%)$ participants, the Kappa coefficient had a mean of $0.59(\mathrm{SD}=0.12)$ ranging from 0.36 to 0.76 . (Table 4 ).

\section{Discussion}

The present study assessed the internal consistency and reliability of the Brazilian Portuguese language version of ICIQ-FLUTSsex in women with urinary incontinence. To our knowledge, this is the first study that assessed the measurement properties of a specific questionnaire to assess sexual dysfunction in women with lower urinary tract dysfunction. The results showed that the ICIQ-FLUTSsex used in this population was quickly applied and showed good internal consistency and moderate test-retest reliability.

Most participants were not nulliparous, the most frequent type of childbirth was vaginal. A cohort study carried out in Sweden with 5,236 women found that having vaginal childbirth, compared to cesarean section, increased the risk of UI by $275 \%$ for the period of 10 years and $67 \% 20$ years after childbirth. 18 Not only the type of childbirth, but pregnancy itself can influence the onset of urinary 
Table 1

\begin{tabular}{lcc}
\hline Sample on the demographic characteristics. & & \\
\hline Variables & N & $\%$ \\
\hline Marital status & 9 & 16.1 \\
Single & 40 & 71.4 \\
Married & 5 & 8.9 \\
$\quad$ Divorced & 2 & 3.6 \\
Widow & & \\
Race & 22 & 39.3 \\
White & 8 & 14.3 \\
Black & 26 & 46.4 \\
Mixed & & \\
Education & 17 & 30.4 \\
Incomplete primary school & 5 & 8.9 \\
Complete primary school & 6 & 10.7 \\
Incomplete high school & 19 & 33.9 \\
Complete high school & 4 & 7.2 \\
Incomplete higher education & 5 & 8.9 \\
Complete higher education or more & & \\
Income (minimum wage) & 31 & 55.4 \\
Upto 1 & 25 & 44.6 \\
1 to 4 & & 57.1 \\
Occupation & 32 & 42.9 \\
Employed & 24 & \\
Unemployed & & \\
& &
\end{tabular}

Table 2

Sample on the gynecological history description.

N

$\%$

\begin{tabular}{lcc}
\hline Hysterectomy & & \\
Yes & 17 & 30.4 \\
No & 39 & 69.6 \\
Type of urinary incontinence & & \\
Urgency incontinence & 9 & 16.1 \\
Stress incontinence & 13 & 23.2 \\
Mixed incontinence & 34 & 60.7
\end{tabular}


Table 3

\begin{tabular}{|c|c|c|}
\hline ICIQ questionnaire & $\mathbf{N}$ & $\%$ \\
\hline \multicolumn{3}{|l|}{ Frequency of urine loss } \\
\hline Never & 3 & 5.4 \\
\hline About once a week or less & 2 & 3.6 \\
\hline Two or three times a week & 7 & 12.5 \\
\hline Once a day & 5 & 8.9 \\
\hline Several times a day & 33 & 58.9 \\
\hline Allthe time & 6 & 10.7 \\
\hline \multicolumn{3}{|l|}{ Amountof urine loss } \\
\hline None & 2 & 3.6 \\
\hline A small amount & 25 & 44.6 \\
\hline A moderate amount & 19 & 33.9 \\
\hline A large amount & 10 & 17.9 \\
\hline \multicolumn{3}{|c|}{ Interference of urine loss in everyday life } \\
\hline 0 & 3 & 5.4 \\
\hline 2 & 5 & 8.9 \\
\hline 3 & 1 & 1.8 \\
\hline 4 & 3 & 5.4 \\
\hline 5 & 7 & 12.5 \\
\hline 6 & 3 & 5.4 \\
\hline 7 & 5 & 8.9 \\
\hline 8 & 3 & 5.4 \\
\hline 9 & 4 & 7.1 \\
\hline 10 & 22 & 39.3 \\
\hline \multicolumn{3}{|l|}{ ICIQ-SF SCORE } \\
\hline No impact & 2 & 3.6 \\
\hline Moderate impact & 1 & 1.8 \\
\hline Severe impact & 7 & 12.5 \\
\hline Very severe impact & 46 & 82.1 \\
\hline
\end{tabular}

\section{Table 4}

Kappa results for the ICIQ-FLUTSsex questionnaire.

2a. Do you have pain or discomfort because of a dry vagina?

2b. How much does this bother you?

3a. To what extent do you feel that your sex life has been spoilt by your urinary symptoms?

0.558

3b. How much does this bother you?

4a. Do you have pain when you have sexual intercourse?

0.696

4b. How much does this bother you?

0.365

5 a. Do you leak urine when you have sexual intercourse?

0.760

5b. How much does this bother you?

0.596 
incontinence. Another cross-sectional study carried out in Brazil with 220 women, two years after having a cesarean section, reported that this type of childbirth does not prevent urinary incontinence. 19

The result on the ICIQ-SF shows that many women have a very serious impact of UI in their QOL. A qualitative study adds that UI has a negative impact on the lives of affected women, changing their daily behavior, imposing restrictions and even compromising their social life. 20 One of the domains affected women with incontinence was their sexuality. ${ }^{21}$ Many may feel embarrassed, because of the risk of urine loss during intercourse. In addition to the fear of urine loss, some women may experience discomfort, such as vaginal pain or dryness.

Analyzing the results, we can infer that the internal consistency on the ICIQ-FLUTSsex questionnaire, assessed by Cronbach's alpha (0.80) was good. According to COSMIN criteria, Cronbach 's alpha must be between 0.70 and 0.95 .22 Comparatively, the Greek version of the same questionnaire obtained an alpha of 0.69 (moderate internal consistency). 23 However, due to the variation of the sample and the intervention during the retest interval, it is not possible to conclude that the Brazilian Portuguese language version is superior to the Greek version.

Analyzing the test-retest reliability values, through Kappa, the results varied from a weak agreement to a substantial agreement. The values of this research ranged from 0.36 to 0.76 , with a mean of 0.59 , which is considered moderate. The item with less agreement was related to pain during intercourse.

According to Terwee et al. ${ }^{24}$ criteria on the interval between repeated questionnaire applied among the participants must be long enough to avoid remembrance of the qustionnaire, although short enough interval is to ensure that clinical change has not occurred, often, a week or two would be appropriate. 24

A limitation in this study was that all the participants were being treated by pelvic physiotherapy, which could possibly interfere with the retest result, having a possible improvement of the symptoms.

The validation of this questionnaire in the Greek version, the retest was answered after 14 to 21 days after the first assessment and its results obtained a Kappa range of 0.61 to 0.86 , which means a substantial value to almost perfect.

As perspectives for future research, it would be relevant to assess responsiveness, a property to detect differences between two points in time (changes in over time) within groups, that is, a clinically relevant change in the scores of a measure ofhealth-related functional status, so that the questionnaire could also be used to monitor the treatment on sexual dysfunction.

The objective of this study was to assess the internal consistency and reliability of the ICIQFLUTSsex and publish it in the Brazilian Portuguese language version, and so, provide another assessment tool for women who have sexual complaints associated with the lower urinary tract. ICIQFLUTSsex has the advantage of being simple, easy to apply and understand, thus it contributes to a better assessment on sexual dysfunctions.

The Brazilian Portuguese language version of ICIQ-FLUTSsex is available, demonstrating as a valid tool, easy to apply, and to assess sexual dysfunction in women with complaints on urinary incontinence.

\section{Authors' contribution}

Andrade BF was responsible for collecting and analyzing the data, writing and discussing the article. Rangel EOR performed data collection and analysis. Guendler JA contributed with data analysis and critical review of the article. Katz L performed a critical review of the article. All authors approved the final version of the manuscript and are publicly responsible for the content of the article. 


\section{References}

1. Hunskaar S, K. Burgio, A.Clark, M.C. Lapitan N, R Nelson, U. Sillén DT. Epidemiology of Urinary ( UI ) and Faecal ( FI ) Incontinence and Pelvic Organ Prolapse ( POP ). Int Cont Soc. 2009;255-312.

2. Wennberg AL, Molander U, Fall M, Edlund C, Peeker R Milsom I. A Longitudinal Population-based Survey of Urinary Incontinence, Overactive Bladder, and Other Lower Urinary Tract Symptoms in Women. Eur Urol. 2009;55(4):783-91.

3. Dedicação AC, Haddad M, Saldanha MES, Driusso P. Comparação da qualidade de vida nos diferentes tipos de incontinência urinária feminina. Rev Bras Fisioter. 2009;13(2):116-22.

4. Melo B, Freitas B, Oliveira V, Menezes R. Correlation between signs and symptoms of urinary incontinence and self-esteem in elderly women. Rev Bras Geriatr Gerontol. 2012;15(1):41-50.

5. Enrique JMB, Binfa LE, Cataldo Alejandra Carrasco V PA, Izaguirre HL, Sarrá SC. Índice De Función Sexual Femenina: Un Test Para Evaluar La Sexualidad De La Mujer. Rev Chil Obs Ginecol. 2004;69(692):118-25.

6. Abdo C, Oliveira Jr W, Moreira Jr E, Fittipaldi J. Perfil sexual da população brasileira: resultado do estudo do comportamento sexual (ECOS) do Brasileiro/Sexual profile of brazilian population: results from Brazilian Study of Sexual Behavior(BSSB). RBM Rev Bras Med. 2002;59(4):250-7.

7. Helena C, Abdo N. Quociente sexual feminino: um questionário brasileiro para avaliar a atividade sexual da mulher. Diagn Trat. 2009;14(2):89-1.

8. Hawthorne G, Sansoni J, Hayes L, Marosszeky N, Sansoni E. Measuring patient satisfaction with health care treatment using the Short Assessment of Patient Satisfaction measure delivered superior and robust satisfaction estimates. J Clin Epidemiol. 2014;67(5):527-37.

9. Martinez EZ. Validade de construto de uma versão em português do Female Sexual Function Index Construct validity of a Portuguese version of the Female Sexual Function Index. 2009;25(11):2333-44.

10. Nunes Tamanini JT, Dambros M, D'Ancona CAL, Rodrigues Palma PC, Rodrigues Netto N. Validação para o português do "International Consultation on Incontinence Questionnaire - Short Form” (ICIQ-SF). Rev Saúde Pública. 2004;38(3):438-44.

11. Katz L, Guendler JA, Flamini MEDM, Flamini RC, Vieira JSBC, Schulze NBB AM. ICIQ-FLUTSsex: uma nova ferramenta para avaliação da Incontinência Urinária e Disfunção Sexual Feminina. Rev Conteporânea GO Fem. 2017;45:15.

\section{Received on March 15, 2019}

Final version presented on November 18, 2019

Approved on December 26, 2019
12. Barbara G, Tabachnick LSF. Using multivariate statistics 4th ed. Boston: Allyn and Bacon; 2001.

13. Sapnas KG, Zeller RA. Minimizing Sample Size When Using Exploratory Factor Analysis for Measurement. J Nursiing Meas. 2002;10(2):135-54.

14. Padilha J, Conte da Silva A, Zarpellon Mazo G, De Godoy Marques CM. Investigação Da Qualidade De Vida De Mulheres Com Incontinência Urinária. Arq Ciênc Saúde UNIPAR. 2018;22(1):43-8.

15. Carvalho MP de, Andrade FP, Peres W, Martinelli T, Simch F, Orcy RB, et al. O impacto da incontinência urinária e seus fatores associados em idosas. Rev Bras Geriatr Gerontol. 2014;17(4):721-30.

16. Silva RS PA. Por dentro da estatística. Educ Contin Saúde einstein. 2012;10(4):165-6.

17. Landis JR, Koch GG. The Measurement of Observer Agreement for Categorical Data. Biometrics. 1977;33(1):159.

18. Gyhagen M, Bullarbo M, Nielsen TF, Milsom I. The prevalence of urinary incontinence 20 years after childbirth: A national cohort study in singleton primiparae after vaginal or caesarean delivery. BJOG An Int J Obstet Gynaecol. 2013;120(2):144-51.

19. Pascon Barbosa AM, Marini G, Piculo F, Rudge CVC, Calderon IMP, Rudge MVC. Prevalência de incontinência urinária e disfunção muscular do assoalho pélvico em primíparas dois anos após parto cesárea: Estudo transversal. Sao Paulo Med J. 2013;131(2):95-9.

20. Henkes DF, Fiori A, Carvalho JAM, Tavares KO FJ. Incontinência urinária: o impacto na vida de mulheres acometidas e o significado do tratamento fisioterapêutico. Sem Ciênc Biol Saúde. 2015;36(2):57-66.

21. Silva AI, Almeida C, Aguiar H, Neves M, Teles MJ. Impacto da incontinência urinária na qualidade de vida sexual da mulher. Femina. 2016;44(3):364-76.

22. Prinsen CAC, Mokkink LB, Bouter LM, Alonso J, Patrick DL, Vet HCW, Terwee CB. COSMIN guideline for systematic reviews of patient-reported outcome measures. Qual Life Res. 2018;27(5):1147-57.

23. Stavros A,* Themistoklis G, Niki K, George G and AA. The Validation of International Consultation on Incontinence Questionnaires in the Greek Language. Neurourol Urodyn. 2012;28(5):395-9.

24. Terwee CB, Bot SDM, de Boer MR, van der Windt DAWM, Knol DL, Dekker J, et al. Quality criteria were proposed for measurement properties of health status questionnaires. J Clin Epidemiol. 2007;60(1):34-42. 